Original Article

\title{
Plasma and peritoneal fluid concentrations of ceftriaxone after intravenous and intraperitoneal administration in horses
}

\author{
J.M. Alonso ${ }^{a}$, R.G. Peccinini ${ }^{\mathrm{b}}$, M.L. Campos ${ }^{\mathrm{b}}$, T.Y. Nitta ${ }^{\mathrm{a}}$, T.Y.M. Akutagawa ${ }^{\mathrm{a}}$, \\ A.P. Crescencio ${ }^{\mathrm{a}}$, A.L.G Alves ${ }^{\mathrm{a}}$, C.A. Rodrigues ${ }^{\mathrm{a}}$, M.J. Watanabe ${ }^{\mathrm{a}}$, C.A. Hussni ${ }^{\mathrm{a}, *}$ \\ ${ }^{a}$ Department of Veterinary Surgery and Anaesthesiology, São Paulo State University (UNESP), School of Veterinary Medicine and Animal Science, Botucatu, \\ Brazil \\ ${ }^{\mathbf{b}}$ Department of Natural Active Principles and Toxicology, São Paulo State University (UNESP), School of Pharmaceutical Sciences, Araraquara, Brazil
}

\section{A R T I C L E I N F O}

\section{Article history:}

Accepted 11 February 2018

\section{Keywords:}

Ceftriaxone

Equine

Intraperitoneal

Intravenous

Minimum inhibitory concentration

\begin{abstract}
A B S T R A C T
Intraperitoneal (IP) use of antimicrobial agents may lead to therapeutic effects with better clinical results than intravenous (IV) administration. The aim of this study was to compare plasma and peritoneal fluid concentrations of ceftriaxone after IP and IV administration in horses, and to evaluate possible adverse effects. One group of five horses received $25 \mathrm{mg} / \mathrm{kg}$ ceftriaxone diluted in $1 \mathrm{~L}$ saline solution by IP catheter once daily for 5 days, while a second group of five horses received $25 \mathrm{mg} / \mathrm{kg}$ ceftriaxone diluted in $250 \mathrm{~mL}$ saline solution by IV injection once daily for 5 days and $1 \mathrm{~L}$ saline solution by IP catheter once daily for 5 days. Peritoneal fluid and plasma were collected to determine ceftriaxone concentrations after the first and fifth administration. IP administration of ceftriaxone resulted in concentrations above a minimum inhibitory concentration (MIC) of $1 \mu \mathrm{g} / \mathrm{mL}$ for $24 \mathrm{~h}$ in peritoneal fluid and for $12 \mathrm{~h}$ in plasma, while IV administration of ceftriaxone resulted in lower peritoneal fluid concentrations, which remained above a MIC of $1 \mu \mathrm{g} / \mathrm{mL}$ for $12 \mathrm{~h}$ in peritoneal fluid and $10 \mathrm{~h}$ in plasma. No adverse effects were observed. Comparisons of ceftriaxone concentrations, time of occurrence of the maximum $\left(\mathrm{T}_{\max }\right)$ and minimum ( $\left.T_{\min }\right)$ concentrations, and the mean residence time (MRT), between the two groups showed that IP administration provided greater availability of cephalosporin in peritoneal fluid. The IP use of ceftriaxone ( $25 \mathrm{mg} / \mathrm{kg}$ diluted in $1 \mathrm{~L}$ saline solution once daily) may be useful for the prophylaxis and/or treatment of peritonitis in horses.
\end{abstract}

(c) 2018 Elsevier Ltd. All rights reserved.

\section{Introduction}

The incidence of colic in horses is $4.2-10.6$ cases/100 horses per year (Tinker et al., 1997). Among these cases, $1.4 \%$ will require surgical intervention (Traub-Dargatz et al., 2001) and approximately 3.1\% will develop septic peritonitis (Mair and Smith, 2005), which is related to mortality rates that exceed $60 \%$ (Schein et al., 1992; Faria et al., 1999; Browning, 2005; Nógrádi et al., 2011). Established therapy for peritonitis in horses is based on a combination of antimicrobial agents and supportive care; despite the adoption of those measures, peritonitis is associated with high mortality, necessitating the application of more effective therapeutic strategies (Browning, 2005).

Ceftriaxone is a third-generation cephalosporin with a broad antibacterial spectrum that has an established clinical efficacy and

\footnotetext{
* Corresponding author.

E-mail address: cahussni@fmvz.unesp.br (C.A. Hussni).
}

high tolerance (Ringger et al., 1996, 1998; Lamb et al., 2002; Bijie et al., 2005; Albarellos et al., 2007). Cephalosporins are antibiotics that inhibit bacterial cell wall synthesis; their activity is time dependent and the best therapeutic outcome is obtained using a dosing regimen that provides longer drug concentrations above the minimal inhibitory concentration (MIC) at the site of infection (Levison and Levison, 2009).

The aim of this study was to compare the profiles of plasma and peritoneal fluid concentrations of ceftriaxone after intraperitoneal (IP) and intravenous (IV) administration in horses and to evaluate the possible adverse effects of IP administration.

\section{Materials and methods}

Animals

Ten healthy male horses were used, comprising six mixed breeds and four Arabian horses, with a mean \pm standard deviation (SD) age of $5.1 \pm 1.3$ years and a mean \pm SD body mass of $317.6 \pm 26.9 \mathrm{~kg}$. The animals were housed in stalls and received Cynodon dactylon hay and water ad libitum. Prior to the start of the study, 
the horses were determined to be healthy on the basis of physical examination and a complete blood count. The experiment was approved by the São Paulo State University Ethics Committee on Animal Experimentation (CEUA approval number 105/2013; date of approval 14 June 2013).

\section{Experimental groups}

This was a randomised study, blocked by breed, in which the horses were divided into two groups of five animals each using the coin toss method, with equal distribution of the breeds between groups; each group was composed of three mixed breed horses and two Arabian horses. The IP group was subjected to a Tenckhoff catheter implantation (Alonso et al., 2017) and received $25 \mathrm{mg} / \mathrm{kg}$ ceftriaxone (Ceftriaxone Sodium, Eurofarma) diluted in $1 \mathrm{~L}$ of saline solution IP, in an infusion of $10 \mathrm{~min}$ duration, every $24 \mathrm{~h}$ for 5 days. The IV group received $25 \mathrm{mg} / \mathrm{kg}$ ceftriaxone through an IV catheter (Abbott Laboratories), placed in the left jugular vein, in an infusion of 5 min duration, every $24 \mathrm{~h}$ for 5 days, along with $1 \mathrm{~L}$ saline solution IP, in an infusion of 10 min duration, every $24 \mathrm{~h}$ for 5 days. The possible occurrence of adverse effects was monitored daily through the evaluation of heart and respiratory rates, colour of mucous membranes, rectal temperature, pain at the injection site, faecal consistency, intestinal motility, alertness and hypersensitivity reactions.

\section{Sample collection}

Serial samples of peritoneal fluid and blood samples were collected into tubes containing ethylene diamine tetra-acetic acid (EDTA). Sample collections were performed before administration and 5, 15 and $30 \mathrm{~min}$, as well as 1, 2, 4, 6, 8, 10, 12, 16 and $24 \mathrm{~h}$, after the first and fifth doses. The peritoneal fluid samples were obtained from the ventral midline of the abdomen through a $21 \mathrm{G}$ hypodermic needle. Plasma samples were obtained through a venous catheter (BD Angiocath) in the right jugular vein prior to disposal of $10 \mathrm{~mL}$ of blood. Both samples were centrifuged $\left(1087 \mathrm{~g}\right.$ for $10 \mathrm{~min}$ ), divided into duplicates and frozen at $-80^{\circ} \mathrm{C}$ for subsequent determination of ceftriaxone concentrations. Plasma and peritoneal fluid protein concentrations were determined using refractometry before, and 1, 3 and 5 days after, ceftriaxone administration.

\section{Determination of plasma and peritoneal fluid ceftriaxone concentrations}

Plasma and peritoneal fluid concentrations of ceftriaxone were determined using ultra-efficient liquid chromatography (UELC; Acquity Class, Waters Corporation) equipped with an ultraviolet (UV)-Vis detector (Campos et al., 2017). The chromatographic analysis was performed in column (Acquity; HSS T3 C18; $2.1 \times 100 \mathrm{~mm} ; 1.8 \mu \mathrm{M}$ ) protected by an HSS C18 column guard (Vanguard; $2.1 \times 5 \mathrm{~mm} ; 1.8 \mathrm{mM}$ ) at $40^{\circ} \mathrm{C}$. The mobile phase was a mixture of methanol and $20 \mathrm{mM}$ ammonium acetate $(21: 79 \mathrm{~V} / \mathrm{V})$ in isocratic mode with detection at $260 \mathrm{~nm}$. The flow rate was $0.4 \mathrm{~mL} / \mathrm{min}$ and the injected sample volume was $1 \mu \mathrm{L}$. The total run time was $8 \mathrm{~min}$. The ratio of the analyte peak area to the peak area of the internal standard (cefoperazone; $1 \mathrm{mg} / \mathrm{mL}$ in water) was used for quantification of the drug (Campos et al., 2017). The method quantification limit was $0.24 \mu \mathrm{g} / \mathrm{mL}$ for peritoneal fluid and $0.49 \mu \mathrm{g} / \mathrm{mL}$ for plasma.

Individual curves of ceftriaxone plasma and peritoneal fluid concentration versus time were constructed for each animal. The maximum concentration $\left(C_{\max }\right)$ and the time of occurrence of the maximum concentration $\left(\mathrm{T}_{\max }\right)$ for both fluids were obtained from the experimental values. The trapezoidal method was used to determine the area under the curve (AUC) from zero to the last sampling time (AUC $0-t)$, and the mean plasma concentration $\left(\mathrm{Cp}_{\mathrm{m}}\right)$ was calculated using the equation: $\mathrm{Cp}_{\mathrm{m}}=\frac{A U C 0-t}{\text { sample interval }}$. The mean residence time (MRT) for both fluids was obtained using statistical moments, assuming the time course of drug concentration in plasma and peritoneal fluid as a distribution time curve. Therefore, it was calculated by the quotient of the first-moment by the zero-moment versus time curves, according to the equation: $M R T=\frac{\int_{\infty}^{0} t C d t}{\int_{\infty}^{0} c d t}($ Gibaldi and Perrier, 1982). The values of the maximum $\left(\mathrm{C}_{\max }\right)$ and minimum $\left(\mathrm{C}_{\min }\right)$ concentrations of ceftriaxone in peritoneal fluid, as well as the respective occurrence times ( $T_{\max }$ and $T_{\min }$ ), were obtained directly from the experimental data, while the peritoneal mean concentration $\left(\mathrm{Cp}_{\mathrm{m}}\right)$ was calculated using the above equation.

The time above the MIC ( $t>$ MIC) was estimated using the ceftriaxone curve concentration as a function of time, calculating the percentage of time that the drug was maintained above a MIC of $1 \mu \mathrm{g} / \mathrm{mL}$, which is the estimated MIC for susceptible Enterobacteriaceae (CLSI, 2014).

\section{Statistical analysis}

Drug concentrations were expressed as mean \pm SD and were compared within each group between days 1 and 5 using a paired $t$ test, and between the IP and IV groups using an unpaired $t$ test. The Mann-Whitney test was used for the evaluation of protein concentrations, comparing the groups between time points, and Wilcoxon's test was used for the paired samples to compare each time point to before administration. Statistical analysis was performed using GraphPad Prism version 5.00. Statistical significance was defined as $P<0.05$

\section{Results}

No statistically significant differences were observed in any of the evaluated pharmacokinetic parameters between the first (day 1) and last (day 5) day of administration in both groups (Table 1 ). After IP administration, IP ceftriaxone concentrations remained above the MIC for $24 \mathrm{~h}$ (Fig. 1A) and plasma concentrations remained above the MIC for $12 \mathrm{~h}$ (Fig. 1B). After IV administration, ceftriaxone concentrations remained above the MIC for $12 \mathrm{~h}$ in the peritoneal fluid (Fig. 1A) and $10 \mathrm{~h}$ in the plasma (Fig. 1B).

The comparisons of ceftriaxone concentration, $\mathrm{T}_{\max }, \mathrm{T}_{\min }$ and MRT between the routes of administration showed that IP administration provided greater availability of ceftriaxone in the peritoneal fluid and a lower peak of ceftriaxone plasma concentrations (Table 2). Following IP drug administration, the MRT of ceftriaxone was higher and drug levels remained above the limit of quantification of the assay throughout the inter-dosing interval. There were no statistically significant differences in the mean and minimum plasma concentrations, nor $\mathrm{T}_{\min }$ in plasma, between the IP and IV groups. There were no significant differences in

Table 1

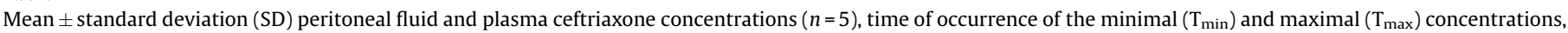
and mean residence time (MRT), for intraperitoneal (IP) and intravenous (IV) administration (25 mg/kg) after the first and fifth days of administration.

\begin{tabular}{|c|c|c|c|c|}
\hline \multirow[t]{2}{*}{ Peritoneal fluid } & \multicolumn{2}{|c|}{ IP } & \multicolumn{2}{|c|}{ IV } \\
\hline & Day 1 & Day 5 & Day 1 & Day 5 \\
\hline Maximum concentration $(\mu \mathrm{g} / \mathrm{mL})$ & $4233.3 \pm 1447.7$ & $5583.0 \pm 2051.6$ & $36.7 \pm 6.3$ & $65.7 \pm 15.8$ \\
\hline Mean concentration $(\mu \mathrm{g} / \mathrm{mL})$ & $965.1 \pm 582.3$ & $779.5 \pm 534.4$ & $14.9 \pm 3.8$ & $17.3 \pm 3.0$ \\
\hline Minimum concentration $(\mu \mathrm{g} / \mathrm{mL})$ & $4.3 \pm 5.0$ & $2.9 \pm 4.2$ & $0.7 \pm 0.5$ & $0.9 \pm 0.4$ \\
\hline $\mathrm{T}_{\max }(\mathrm{h})$ & $0.2 \pm 0.2$ & $0.1 \pm 0.1$ & $2.8 \pm 1.1$ & $1.2 \pm 0.4$ \\
\hline $\mathrm{T}_{\min }(\mathrm{h})$ & $24 \pm 0.0$ & $22.4 \pm 1.6$ & $16 \pm 2.2$ & $15.2 \pm 2.3$ \\
\hline \multirow[t]{2}{*}{ Plasma } & \multicolumn{2}{|c|}{ IP } & \multicolumn{2}{|c|}{ IV } \\
\hline & Day 1 & Day 5 & Day 1 & Day 5 \\
\hline Maximum concentration $(\mu \mathrm{g} / \mathrm{mL})$ & $40.9 \pm 4.7$ & $45.4 \pm 7.9$ & $199.2 \pm 69.3$ & $160.9 \pm 32.2$ \\
\hline Mean concentration $(\mu \mathrm{g} / \mathrm{mL})$ & $13.3 \pm 3.0$ & $9.6 \pm 0.9$ & $14.9 \pm 5.2$ & $9.1 \pm 1.2$ \\
\hline Minimum concentration $(\mu \mathrm{g} / \mathrm{mL})$ & $0.7 \pm 0.3$ & $0.5 \pm 0.1$ & $0.8 \pm 0.2$ & $0.9 \pm 0.3$ \\
\hline $\mathrm{T}_{\max }(\mathrm{h})$ & $2.4 \pm 0.4$ & $1.2 \pm 0.2$ & - & - \\
\hline $\mathrm{T}_{\min }(\mathrm{h})$ & $17.6 \pm 1.6$ & $16 \pm 2.2$ & $12 \pm 1.1$ & $16.8 \pm 2.0$ \\
\hline MRT (h) & $4.5 \pm 0.3$ & $3.8 \pm 0.8$ & $1.9 \pm 0.2$ & $2.5 \pm 0.5$ \\
\hline
\end{tabular}


A

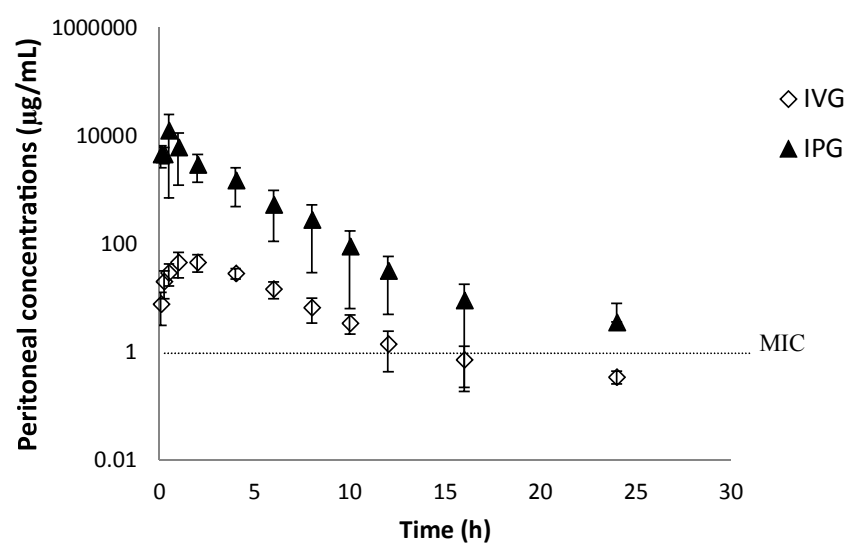

B

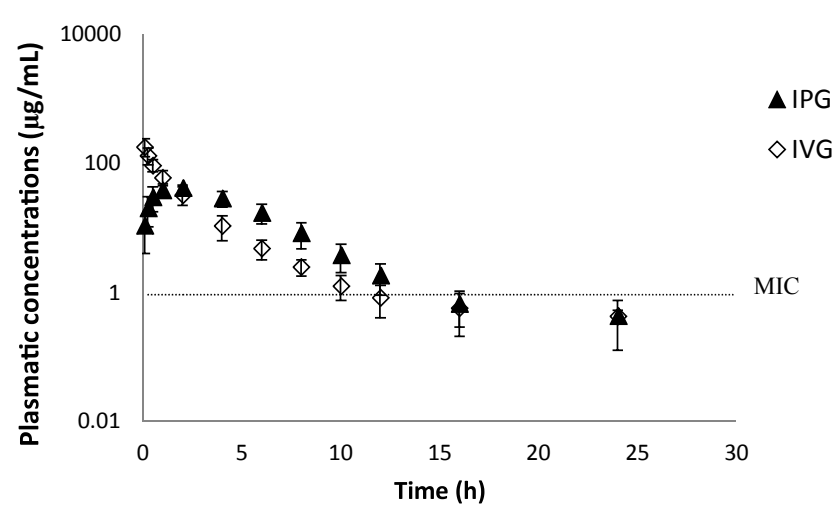

Fig. 1. Mean \pm standard deviation (SD) of peritoneal fluid (A) and plasma (B) concentrations of ceftriaxone after intraperitoneal (IP) and intravenous (IV) administration at a dose of $25 \mathrm{mg} / \mathrm{kg}$.

Table 2

Mean \pm standard deviation (SD) peritoneal fluid and plasma ceftriaxone concentrations $(n=10)$, times of occurrence of the minimal $\left(\mathrm{T}_{\min }\right)$ and maximal $\left(\mathrm{T}_{\max }\right)$ concentrations, and mean residence times (MRTs), after intraperitoneal (IP) and intravenous (IV) administration of $25 \mathrm{mg} / \mathrm{kg}$ ceftriaxone.

\begin{tabular}{lcc}
\hline Peritoneal fluid & IP & IV \\
\hline Maximum concentration $(\mu \mathrm{g} / \mathrm{mL})$ & $4908.2 \pm 1818.8$ & $51.2 \pm 19.0^{*}$ \\
Mean concentration $(\mu \mathrm{g} / \mathrm{mL})$ & $872.3 \pm 536.1$ & $16.1 \pm 3.5^{*}$ \\
Minimum concentration $(\mu \mathrm{g} / \mathrm{mL})$ & $3.8 \pm 4.2$ & $0.8 \pm 0.5^{*}$ \\
$\mathrm{~T}_{\max }(\mathrm{h})$ & $0.2 \pm 0.1$ & $2.0 \pm 1.1^{*}$ \\
$\mathrm{~T}_{\min }(\mathrm{h})$ & $23.2 \pm 2.5$ & $15.6 \pm 4.8^{*}$ \\
\hline & & \\
Plasma & $\mathrm{IP}$ & $\mathrm{IV}$ \\
\hline Maximum concentration $(\mu \mathrm{g} / \mathrm{mL})$ & $43.2 \pm 6.6$ & $180.0 \pm 54.8^{*}$ \\
Mean concentration $(\mu \mathrm{g} / \mathrm{mL})$ & $11.4 \pm 2.9$ & $12.0 \pm 4.7$ \\
Minimum concentration $(\mu \mathrm{g} / \mathrm{mL})$ & $0.5 \pm 0.1$ & $0.7 \pm 0.3$ \\
$\mathrm{~T}_{\max }(\mathrm{h})$ & $1.9 \pm 0.3$ & - \\
$\mathrm{T}_{\min }(\mathrm{h})$ & $16.8 \pm 1.3$ & $14.4 \pm 4.2$ \\
MRT $(\mathrm{h})$ & $4.2 \pm 0.7$ & $2.2 \pm 0.5^{*}$ \\
\hline
\end{tabular}

* Statistically significant difference between groups $(P<0.05)$.

peritoneal fluid protein concentrations of ceftriaxone between groups (Fig. 2). Using the estimated MIC for Enterobacteriaceae $(1 \mu \mathrm{g} / \mathrm{mL}), t>$ MIC in the peritoneal fluid was $100 \%$ for the IP group and $50 \%$ for the IV group. In the plasma, $t>$ MIC was $50 \%$ for the IP group and $41.7 \%$ for the IV group.

\section{Discussion}

The antibacterial action of antibiotics depends on reaching the minimal inhibitory concentration. Therefore, when changing the route or method of administration, it is important to investigate how this affects drug concentrations. Our study demonstrated that there were no significant differences in IV or IP ceftriaxone concentrations and MRT between days 1 and 5 after IP and IV administration (Table 1 ). This indicates that there was no significant accumulation until the fifth dose and, even though the drug was administered multiple times (five times), each next daily dose was not dependent on the previous dose in order to reach an active concentration, and thus can be regarded as multiple administration of single doses.

The MIC of ceftriaxone for susceptible Enterobacteriaceae reported in humans is $1 \mu \mathrm{g} / \mathrm{mL}$ (CLSI, 2014).

Escherichia coli, one of the potential causes of colic in horses, has a MIC of $0.003 \mu \mathrm{g} / \mathrm{mL}$ in cats (Albarellos et al., 2007) and cattle (Soback and Ziv, 1988). In the absence of a specific MIC for the main aetiological agents of peritonitis in horses, the highest value for the group of Enterobacteriaceae $(1 \mu \mathrm{g} / \mathrm{mL})$ was selected in this study as the baseline MIC.

The maintenance of IP concentrations of ceftriaxone above the MIC for Enterobacteriaceae $(1 \mu \mathrm{g} / \mathrm{mL})$ for $24 \mathrm{~h}$ and above the MIC in plasma for $12 \mathrm{~h}$ demonstrated that the IP route promoted adequate drug levels for antimicrobial activity in the interval between administrations. Since the pharmacological effect of ceftriaxone is closely related to the time exceeding the MIC (Albarellos et al., 2007), higher and longer lasting peritoneal fluid concentrations of ceftriaxone after IP administration compared to IV administration suggest that the IP route may be therapeutically advantageous and might increase survival rates in horses affected by peritonitis.

The value $t>$ MIC of $100 \%$ for IP administration of ceftriaxone is also relevant. For cephalosporins, a dosing interval resulting in a $t>$ MIC of $35-40 \%$ corresponds to a bacteriostatic effect, while a $t>$ MIC of $60-70 \%$ is required for a bactericidal effect (Craig, 1988; Toutain et al., 2002; Albarellos et al., 2007). The mechanism behind this is not fully understood; however, even at concentrations below half the MIC, ceftriaxone results in increased phagocytosis and reduced intracellular survival of bacteria (Craig, 1988; Tullio et al., 1994; Toutain et al., 2002).

For time-dependent antimicrobial agents, such as ceftriaxone, it is desirable to reach concentrations above the MIC at the infected site for as long as possible, since the effectiveness depends on the amount of time the antibiotic is available to bind to microorganisms. The requisite pharmacodynamic parameter can be simplified to the time that serum concentrations remain above the MIC during the dosing interval $(t>$ MIC) (Levison and Levison, 2009). The maintenance of high concentrations in the peritoneal cavity during the administration interval is a major advantage of IP administration for the treatment of peritonitis.

The recommended dose of ceftriaxone for horses is $25-50 \mathrm{mg} /$ $\mathrm{kg}$ every $12 \mathrm{~h}$ (Levison and Levison, 2009). A dose of $50 \mathrm{mg} / \mathrm{kg}$ is often used in adult animals (Ringger et al., 1996), whereas $25 \mathrm{mg} /$ $\mathrm{kg}$ is used in foals (Ringger et al., 1998). In the present study, the use of $25 \mathrm{mg} / \mathrm{kg}$ via the IP route was sufficient to obtain therapeutic concentrations for $24 \mathrm{~h}$ in adult horses. Thus, the use of the IP route allowed a reduction to half the dose for an adult horse, while doubling the duration of action, which could possibly reduce any toxic effects of the drug and lower the treatment costs. At the first sampling point, $\mathrm{T}_{\max }$ in the peritoneal fluid after IP administration was not as high as expected. This is likely to have occurred because ceftriaxone was administered through the left flank and gradually spread by gravitational and motility action to the ventral aspect of the abdomen, where the samples were harvested. 
A

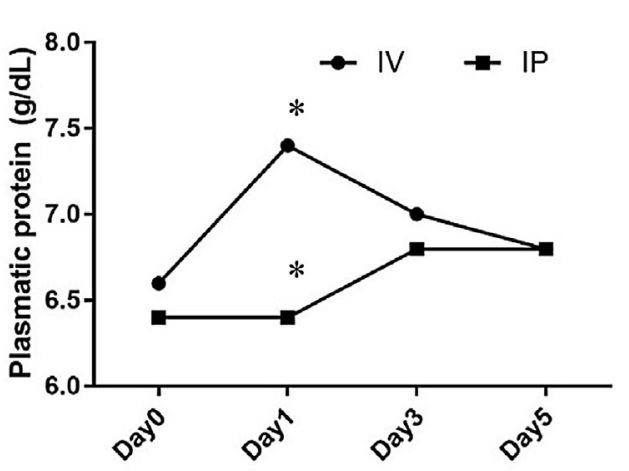

B

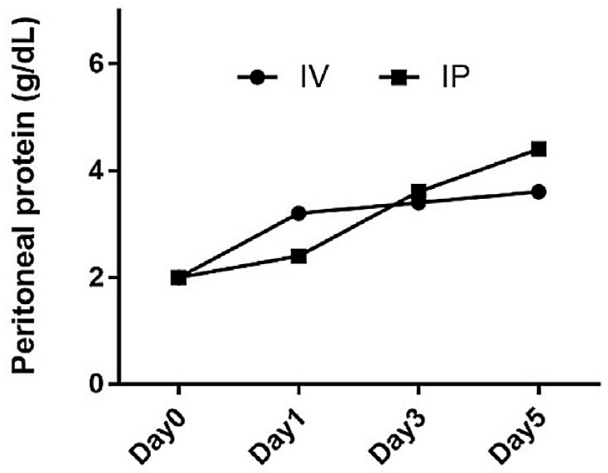

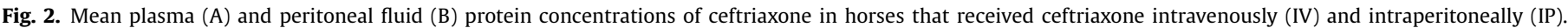
*Significant difference between groups $(P=0.036)$.

Our results showed that IV administration of ceftriaxone leads to higher plasma concentrations than IP administration; although this may be seen as an advantage, it could also be related to a higher incidence of adverse effects (Gardner and Aucoin, 1994; Ringger et al., 1998). Conversely, on the basis of lower plasma concentrations, the incidence of adverse effects after IP administration is expected to be lower following IP administration. Concerning side effects, our results differed from those of Ringger et al. (1998) and Gardner and Aucoin (1994), who reported the occurrence of colitis, depression and decreased appetite after the administration of intravenous ceftriaxone in healthy horses at doses of $50 \mathrm{mg} / \mathrm{kg}$ and $14 \mathrm{mg} / \mathrm{kg}$, respectively. No adverse effects were observed with the dose used in the present study. This is in agreement with studies in human beings reporting a low incidence of adverse effects for this antimicrobial agent (Moskovitz, 1984; Brodgen and Ward, 1988; Freitas, 2014). The absence of clinical signs suggesting the occurrence of adverse effects after drug administration for both administration routes allows us to consider them to be safe in healthy horses.

\section{Conclusions}

The IP use of ceftriaxone resulted in peritoneal fluid concentrations above a MIC of $1 \mu \mathrm{g} / \mathrm{mL}$ for $24 \mathrm{~h}$, suggesting the usefulness of an IP dosage regimen of $25 \mathrm{mg} / \mathrm{kg}$ at $24 \mathrm{~h}$ intervals. After IV administration, ceftriaxone concentrations remained above the MIC for $12 \mathrm{~h}$ in peritoneal fluid and $10 \mathrm{~h}$ in plasma. Our results suggest that the IP route promotes higher and longer lasting peritoneal fluid concentrations of ceftriaxone compared to IV administration; this may be therapeutically advantageous and might increase survival rates in horses affected by peritonitis. Further studies on clinical cases of horses with peritonitis are needed to establish the effectiveness of this therapy.

\section{Conflict of interest statement}

None of the authors of this paper has a financial or personal relationship with other people or organisations that could inappropriately influence or bias the content of the paper.

\section{Acknowledgements}

The authors acknowledge the National Council for Scientific and Technological Development (CNPq grant number 309254/2015-9) and São Paulo State Foundation Research (FAPESP grant number 2013/13799-7 and 2011/11239-9) for financial support.

\section{References}

Albarellos, G.A., Kreil, V.E., Landoni, M.F., 2007. Pharmacokinetics of ceftriaxone after intravenous, intramuscular and subcutaneous administration to domestic cats. Journal of Veterinary Pharmacology and Therapeutics 30, 345-352.

Alonso, J.M., Nitta, T.Y., Akutagawa, T.Y.M., Crescencio, A.P., Takahira, R.K., dos Santos, B., Alves, A.L.G., Watanabe, M.J., Rodrigues, C.A., Peccinini, R.G., et al., 2017. Evaluation of Tenckhoff catheter use and ceftriaxone intraperitoneal administration in horses. Journal of Equine Veterinary Science 53, 55-63.

Bijie, H., Kulpradist, S., Manalaysay, M., Soebandrio, A., 2005. In vitro activity, pharmacokinetics, clinical efficacy, safety and pharmacoeconomics of ceftriaxone, compared with third and fourth generation cephalosporins: review. Journal of Chemotherapy 17, 3-24.

Brodgen, R.N., Ward, A., 1988. Ceftriaxone. A reappraisal of its antibacterial activity and pharmacokinetic properties, and an update on its therapeutic use with particular reference to once-daily administration. Drugs 35, 604-645.

Browning, A., 2005. Diagnosis and management of peritonitis in horses. In Practice 27, 70-75.

Campos, M.L., Alonso, J.M., Santos, M.E., Oliveira, J.A., Hussni, C.A., Peccinini, R.G., 2017. Ceftriaxone pharmacokinetics by new simple and sensitive ultra-highperformance liquid chromatography method. Diagnostic Microbiology and Infectious Disease 88, 95-99.

CLSI (Clinical and Laboratory Standards Institute), 2014. Performance Standards for Antimicrobial Susceptibility Testing: Twenty-Second Informational Supplement M100-S24. CLSI, Wayne, PA, USA.

Craig, W.A., 1988. Pharmacokinetic/pharmacodynamic parameters: rationale for antibacterial dosing of mice and men. Clinical Infectious Diseases 26, 1-12.

Faria, E.P., Marques, J.R., Alves, G.E.S., 1999. Características celulares e bioquímicas do líquido peritoneal de equinos submetidos à peritonite experimental. Arquivo Brasileirode Medicina Veterinária e Zootecnia 51, 335-344.

Freitas, R.M., 2014. Mecanismo de ação, efeitos farmacológicos e reações adversas da ceftriaxona: uma revisão de literatura. Revista Eletrônica de Farmacia 11, 10.

Gardner, S.Y., Aucoin, D.P., 1994. Pharmacokinetics of ceftriaxone in mares. Journal of Veterinary Pharmacology and Therapeutics 17, 155-156.

Gibaldi, M., Perrier, D., 1982. Pharmacokinetics, 2nd ed. Drugs and the Pharmaceutical Sciences, vol. 15. Marcel Dekker, New York, USA 504 pp.

Lamb, H.M., Ormrod, D., Scott, L.J., Figgitt, D.P., 2002. Ceftriaxone: an update of its use in the management of community-acquired and nosocomial infections. Drugs 62, 1041-1089.

Levison, M.E., Levison, J.H., 2009. Pharmacokinetics and pharmacodynamics of antibacterial agents. Infectious Diseases Clinics of North America 23, 791-815.

Mair, T.S., Smith, L.J., 2005. Survival and complications rates in 300 horses undergoing surgical treatment of colic. Part 2: short term complications. Equine Veterinary Journal 37, 303-309.

Moskovitz, B.L., 1984. Clinical adverse effects during ceftriaxone therapy. American Journal of Medicine 77, 84-88.

Nógrádi, N., Tóth, B., Macgillivray, K.C., 2011. Peritonitis in horses: 55 cases (20042007). Acta Veterinaria Hungarica 59, 2.

Ringger, N.C., Brown, M.P., Kohlepp, S.J., Growall, R.R., Merrit, K., 1998. Pharmacokinetics of ceftriaxone in neonatal foals. Equine Veterinary Journal 30, $163-165$.

Ringger, N.C., Pearson, E.G., Gronwall, R., 1996. Pharmacokinetics of ceftriaxone in healthy horses. Equine Veterinary Journal 28, 476-479.

Schein, M., Hirshberg, A., Hashnonai, M., 1992. Current surgical management of severe intra-abdominal infection. Surgery 112, 489-496.

Soback, S., Ziv, G., 1988. Pharmacokinetics and bioavailability of ceftriaxone administered intravenously and intramuscularly to calves. American Journal of Veterinary Research 49, 535-538.

Toutain, P.L., Del Castillo, J.R.E., Bousquet-Me'lou, A., 2002. The pharmacokineticpharmacodynamic approach to a rational dosage regimen for antibiotics. Research in Veterinary Science 73, 105-114. 
Tinker, M.K., White, N.A., Lessard, P., Thatcher, C.D., Pelzer, K.D., Davis, B., Carmel, D. K., 1997. Prospective study of equine colic incidence and mortality. Equine Veterinary Journal 29, 448-453.

Traub-Dargatz, J.L., Kopral, C.A., Seitzinger, A.H., Garber, L.P., Forde, K., White, N.A. 2001. Estimate of the national incidence of and operation-level risk factors for colic among horses in the United States, spring 1998 to spring 1999. Journal of the American Veterinary Medical Association 219, 67-71.

Tullio, V., Cuffini, A.M., Cavallo, R., Alloco, A., Carlone, N.A., 1994. Effect of ceftriaxone on the phagocytosis and intracellular killing of Staphylococcus aureus by human macrophages. Journal of Chemotherapy 6, 177-183. 